\title{
Potential of lactic acid bacteria for the reduction of fumonisin exposure in African fermented maize based foods
}

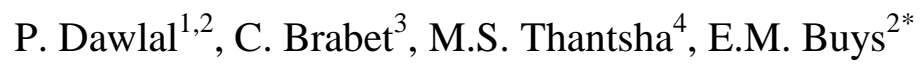 \\ ${ }^{1}$ Council for Scientific and Industrial Research (CSIR), Biosciences, PO Box 395, Pretoria, 0001, South Africa \\ 2 University of Pretoria, Department of Food Science, Pretoria, 0002, South Africa \\ 3 Centre de coopération internationale en recherche agronomique pour le développement (CIRAD), UMR - \\ Qualisud, TA B-95/16, 73 rue J.F. Breton, 34398 Montpellier Cedex 5, France \\ ${ }^{4}$ University of Pretoria, Department of Microbiology and Plant Pathology, Pretoria, 0002, South Africa \\ *Email: elna.buys@up.ac.za
}

\begin{abstract}
:
Maize, which contributes a large portion of the African diet and serves as the base substrate for many fermented cereal products, has been reported to be contaminated with fumonisins. This study aimed to evaluate in vitro the ability of predominant lactic acid bacteria (LAB) in African traditional fermented maize based foods (ogi and mahewu) to bind fumonisins $\mathrm{B} 1$ (FB1) and B2(FB2), as well as the stability of the complex at different $\mathrm{pH}$ and temperatures, in particular observed during ogi fermentation and under its storage conditions (time, temperature). The percentage of bound fumonisins was calculated after analysing the level of fumonisins not bound to LAB after a certain incubation time, by high performance liquid chromatography. The results revealed the ability of all tested LAB strains to bind both fumonisins, with binding efficiency varying between strains and higher for FB2. Binding of fumonisins increased with a decrease in $\mathrm{pH}$ from 6 to 4 (observed during ogi fermentation process) and from 4 to 2 (acidic $\mathrm{pH}$ in the stomach), and an increase in temperature (from $30^{\circ} \mathrm{C}$ to $37^{\circ} \mathrm{C}$ ). The percentage of fumonisins (B1 and $\mathrm{B} 2$ ) bound to $\mathrm{LAB}$ at $\mathrm{pH}$ 4 decreased after 6 days of storage at $30^{\circ} \mathrm{C}$ for all LAB strains, except for $L$. plantarum (R1096) for which it increased. Lactobacillus species (L. plantarum and L. delbrueckii) were the most efficient in binding fumonisins (B1 and B2), whereas Pediococcus sp. the less efficient. Therefore, the Lactobacillus strains tested in this study can be recommended as potential starter cultures in African traditional fermented maize based foods to provide detoxifying and probiotic properties.
\end{abstract}


Keywords: mycotoxins, fumonisins, fermented maize, ogi, mahewu, detoxification, binding, lactic acid bacteria

\section{Introduction}

The majority of humanity's food supply consists of a wide variety of cereal grains with maize, rice, wheat and barley being the world's four major ones (FAO, 2014; Pereira et al., 2014). In Africa, maize is the most produced cereal crop and a major staple food for majority of the population (FAO, 2014; Macauley and Ramadjita, 2015), and traditional fermented maize based products (e.g. ogi, kenkey, mawe, mahewu) are particularly important (FAO, 1999). Maize, as other cereals, is at risk of infection by mycotoxigenic fungi and their related mycotoxins (Pereira et al., 2014). Mycotoxins are secondary fungal metabolites, with major concern for public health since they can cause acute or chronic intoxications to humans, which are sometimes fatal, due to their various toxic effects (carcinogenic, hepatotoxic, nephrotoxic, neurotoxic, immunotoxic, oestrogenic) (AFSSA, 2006; Zain, 2011). Most mycotoxins are chemically and heat stable, resilient to storage and processing conditions. In particular, they are not easily destroyed by cooking processes (Valiuškaitè et al., 2006; Kabak, 2009). In countries where food is scarce and subsistence farming forms the major source of food, cereals contaminated with mycotoxins are consumed (Marasas et al., 2008). Moreover, traditional fermented cereal foods are cheap and relatively easy to prepare and this accounts for their popularity amongst most African population groups. As a consequence of poverty, poor food security and malnutrition, exposure to mycotoxins is high in Africa (Marasas et al., 2008).

Several studies have reported the occurrence of mycotoxins in maize, in particular in Africa, fumonisins being among the most prevalent ones with high contamination rates and levels that can exceed $10 \mu \mathrm{g} / \mathrm{g}$ (Chilaka et al., 2016; Mngqawa et al., 2016; Okeke et al., 2015; Vismer et al. 2015; Udomkun et al., 2017). Fumonisins are a group of mycotoxins primarily produced by Fusarium verticillioides and F. proliferatum (Dawlal et al., 2010; IARC, 2015; Ferrigo et al., 2016). They consist of a long hydroxylated hydrocarbon chain (20 carbon atoms) containing methyl and amino groups and in which the hydroxyl groups on C14 and C15 are esterified with tricarboxylic acid(TCA) (Abrunhosa et al., 2016). Fumonisins B1 (FB1) and B2 (FB2) are the most commonly found in food and feed, with FB1 the most abundant (IARC, 2015; Abrunhosa et al., 2016; Ferrigo et al., 2016). FB1 is also the most toxic fumonisin. An exposure to this toxin has been associated with high incidence of human 
oesophageal cancer in various parts of Africa (Zain, 2011).

Different methods have been developed for the reduction and detoxification of mycotoxins in food and feed (Reddy et al., 2010; Jard et al., 2011; Karlovsky et al., 2016). Among these methods, the use of lactic acid bacteria (LAB) is regarded as a promising approach due to their ability to bind mycotoxins, including fumonisins (Dalié et al., 2010). Niderkorn et al. (2006a, b) investigated in vitro the interaction between fermentative bacteria and fumonisins B1 and B2 and they reported that LAB belonging to the genera Lactobacillus, Pediococcus, Streptococcus, Lactococcus and Leuconostoc, are able to bind fumonisins, but with great differences among strains. Binding efficiency was higher for FB2 and affected by the $\mathrm{pH}$, with binding nearly $0 \%$ at neutral $\mathrm{pH}$. In a further investigation, Niderkorn et al. (2009) identified peptidoglycan and TCA as important components of LAB cell wall and fumonisins, respectively, involved in the binding interaction. These studies revealed a field of research that can provide unique, dual benefits in the area of African fermented maize based foods due to LAB generally recognised as probiotic strains and being a safe, possibly stable, fumonisin detoxifying agent.

Ogi is an acid fermented cereal gruel mademainly from maize and consumed widely in West African countries (e.g. Nigeria, Benin, Togo and Ghana) where it is a staple food, used as infant weaning foods, breakfast cereal and convenient meal for sick and convalescent individuals. The traditional process of ogi consists in grain steeping in water for 1 to 3 days, wet milling, wet sieving to remove bran, decanting and fermentation of the sievate for 1 to 3 days (Nago et al., 1998; Nwosu and Oyeka, 1998; Ijabadeniyi, 2007; Omemu, 2011, Fayemi, 2016). During the fermentation step, it was reported that the temperature of fermenting maize remains relatively constant between $28^{\circ} \mathrm{C}$ and $30^{\circ} \mathrm{C}$ (Omemu, 2011; Fayemi, 2016) and the pH decreases from approximatively 6 to 4 (Nwosu and Oyeka, 1998; Omemu, 2011; Fayemi, 2016). Microbiological studies also showed the major involvement of LAB in ogi fermentation(Agati et al., 1998; Nago et al., 1998; Fayemi, 2016), with LAB population increasing from $4.3 \times 10^{10} \mathrm{cfu} / \mathrm{g}$ to $7.9 \times 10^{10} \mathrm{cfu} / \mathrm{g}$ (Omemu, 2011) or reaching values of $10^{9} \mathrm{cfu} / \mathrm{g}$ (Nago et al., 1998). The predominant LAB included L. plantarum, L. delbrueckii, L.brevis, L. fermentum and its biotype L. cellobiosus, and Pediococcus pentosaceus (Nago et al., 1998; Nwosu and Oyeka, 1998; Ijabadeniyi, 2007; Adebayo-tayo and Onilude, 2008; Afolabi and Akintokun, 2008; Omemu, 2011; Fayemi, 2016).Mugcoba (2001), Holzapfel and Taljaard (2004), Katangole (2008), have all indicated L. delbrueckii and L. brevis to be the 
most prevalent LAB during the fermentation of mahewu which is a South African traditional maize based product similar to ogi.

The aim of this study was to evaluate in vitro the interaction between predominant $\mathrm{LAB}$ in African traditional fermented maize based foods (ogi and mahewu) and fumonisins B1and $\mathrm{B} 2$, as well as the stability of the bound complexat different $\mathrm{pH}$ and temperatures, in particular observed during ogi fermentation, and under its storage conditions (time, temperature).

\section{Materials and Methods}

\section{LAB strains and media}

Three LAB strains belonging to species that predominate in African traditional fermented maize based foods (ogi and mahewu) were tested in this study: two LAB strains, $L$. plantarum (FS2) and Pediococcus pentosaceus (D39), with probiotic characteristics, isolated from Nigerian ogi (Fayemi, 2016), and L. delbrueckii ssp. delbrueckii (CIP 57.8T) isolated from sour grain mash and sourced from the Pasteur Institute, France. Lactobacillus plantarum (R1096) sourced from Lallemand SAS, France, was selected as positive control strain as it had amongst the highest binding of FB1 and FB2 (Niderkorn et al., 2006a).

De Man, Rogosa, Sharpe (MRS) Broth (Biokar, BK070HA)and MRS agar (Biokar,BK089HA) (de Man et al., 1960) were used for the culture of LAB strains.

All LAB strains were cultivated and stored on MRS agar slants at $4^{\circ} \mathrm{C}$ for 3 months, and for long term conservation, cryopreserved at $-80^{\circ} \mathrm{C}$ in $12.5 \%$ glycerol (Jacobs, 1991) and on microbeads (MAST Diagnostics, France).

\section{Fumonisins B1 and B2}

Fumonisins B1 (10 mg, F1147) and B2 (10 mg, F3771) were purchased from Sigma Aldrich, France. They were each dissolved in $10 \mathrm{ml}$ of $50 \%$ acetonitrile to obtain 40 amber vials with a concentration of $250 \mu \mathrm{g} / \mathrm{mlwhich}$ were stored at $-20^{\circ} \mathrm{C}$. A standardized concentration of 10 $\mu \mathrm{g} / \mathrm{ml}$ for each fumonisin was used across all tests during experimentation according to the method developed by Niderkorn et al. (2006a).

\section{Determination of the binding ratio between LAB and fumonisins}

The method described by Niderkorn et al. (2006a) was used in this study with a few modifications. For each LAB strain, two Erlenmeyer flasks containing $200 \mathrm{ml}$ of MRS 
brothwere inoculated with a fresh, single colony from 24-48 h culture on MRS agar, and incubated at $37^{\circ} \mathrm{C}$ (optimal growth temperature) for $24 \mathrm{~h}$. At the end of the incubation time, the two broth cultures were homogenized and an aliquot of $2 \mathrm{ml}$ was used for quantifying the LAB concentration. A standardized concentration of LAB cells $\left(10^{13} \mathrm{cfu} / \mathrm{ml}\right)$ was systematically obtained and used for all strains across all tests.

Thereafter, the two broth cultures were each aseptically transferred to a sterile $250 \mathrm{ml}$ centrifuge bottle and centrifuged at $3000 \mathrm{x}$ g for $10 \mathrm{~min}$ at $<10^{\circ} \mathrm{C}$. The supernatant was removed and the LAB cell pellet was re-suspended and washed (x3) in $100 \mathrm{ml}$ of $0.01 \mathrm{M}$ phosphate buffer solution (PBS) $\mathrm{pH} 7.4$ by mixing then centrifuging under the same conditions. After the last wash step, the bacterial pellet from one of the two broth cultures was re-suspended in $2 \mathrm{ml}$ of $0.1 \mathrm{M}$ citrate phosphate buffer (CPB) $\mathrm{pH} 4$ containing $10 \mu \mathrm{g} / \mathrm{ml}$ of FB1 and $10 \mu \mathrm{g} / \mathrm{ml}$ of FB2 (fumonisin buffer solution). After homogenization with vortex, the $2 \mathrm{ml}$ were split into $1 \mathrm{ml}$ each transferred to a $2 \mathrm{ml}$ Eppendorf tube (test samples in duplicate).The bacterial pellet from the second broth culturewas re-suspended in $2 \mathrm{ml}$ of $0.1 \mathrm{M}$ $\mathrm{CPB} \mathrm{pH} 4$ and after homogenization, $1 \mathrm{ml}$ was transferred to a $2 \mathrm{ml}$ Eppendorf tube (negative control sample excluding FB1 and FB2). For the positive control samples (excluding LAB cells), $1 \mathrm{ml}$ of the fumonisin buffer solution was transferred to a2ml Eppendorf tube, in duplicate. All the samples were incubated at $30^{\circ} \mathrm{C}$ for $1 \mathrm{~h}$ with agitation (480rpm) and for $23 \mathrm{~h}$ without agitation, then centrifuged at $3000 \mathrm{x}$ g for $10 \mathrm{~min}$ at $<5^{\circ} \mathrm{C}$. The supernatants were each transferred to $2 \mathrm{ml}$ amber vials and stored at $4^{\circ} \mathrm{C}$ until the analysis of fumonisins (B1 and B2) by using high performance liquid chromatography (HPLC).

\section{Determination of $L A B$ concentration}

LAB concentration in the culture broth was estimated by measuring the absorbance at $600 \mathrm{~nm}$ $\left(\mathrm{OD}_{600}\right)$ then comparing to standard curves previously obtained for each LAB strain by relating colony forming units (cfu) per $\mathrm{ml}$ from plate counts and absorbance measurements over an array of LAB concentrations.

\section{Effect of $\mathrm{pH}$ and temperature on the binding ratio}

Ogi fermentation occurring around $30^{\circ} \mathrm{C}$ with the $\mathrm{pH}$ decreasing from approximatively 6 to 4 , the binding ratio between $\mathrm{LAB}$ and fumonisins $\mathrm{B} 1$ and $\mathrm{B} 2$ was also determined at $\mathrm{pH} 5$ and $\mathrm{pH}$ 6. For that, the method detailed above (binding ratio method) was repeated with variation in $\mathrm{pH}$ of the fumonisin buffer solution. Tests were performed using $0.1 \mathrm{M} \mathrm{CPB}$ which was 
adjusted to $\mathrm{pH} 5$ and $\mathrm{pH} 6$.

The binding ratio method was also modified to simulate the optimal growth temperature of $\mathrm{LAB}$ strains i.e. $37^{\circ} \mathrm{C}$, as this may influence the dominance of the strains during the fermentation of maize based foods, such as ogi and mahewu. Samples were prepared as detailed above using $0.1 \mathrm{M} \mathrm{CPB}$ which was adjusted to $\mathrm{pH} 4, \mathrm{pH} 5$ and $\mathrm{pH}$ 6, individually. Each set of samples at different $\mathrm{pH}$ was incubated at $37^{\circ} \mathrm{C}$ for $1 \mathrm{~h}$ with agitation (480rpm) and for $23 \mathrm{~h}$ without agitation, thereafter supernatants were recovered and stored at $4{ }^{\circ} \mathrm{C}$ until fumonisin analysis by HPLC.

The binding ratio was determined at a lower $\mathrm{pH}$ of 2 and an incubation temperature of $37^{\circ} \mathrm{C}$ found during human gastric digestion. Samples were prepared as previously indicated using $0.1 \mathrm{M}$ CPB which was adjusted to $\mathrm{pH} 2$. After incubation at $37^{\circ} \mathrm{C}$ for $1 \mathrm{~h}$ with agitation (480rpm) and for $23 \mathrm{~h}$ without agitation, supernatants were recovered and stored at $4^{\circ} \mathrm{C}$ until fumonisin analysis by HPLC.

\section{Effect of simulated ogi storage conditions in vitro on binding stability}

Preparation of samples followed the initial binding ratio method mentioned above in $0.1 \mathrm{M}$ $\mathrm{CPB}$ at $\mathrm{pH} 4$. The samples were then incubated at $30^{\circ} \mathrm{C}$ for $1 \mathrm{~h}$ with agitation (480rpm) and without agitation for $23 \mathrm{~h}$ followed by 6 days for simulating ogi storage conditions. Supernatants were recovered and stored at $4{ }^{\circ} \mathrm{C}$ until fumonisin analysis by HPLC.

\section{Fumonisin analysis by HPLC}

Fumonisins B1 and B2 were quantified in the supernatants of all samples (test samples, positive and negative controls) stored at $4^{\circ} \mathrm{C}$ by HPLC coupled with a fluorescence detector (Shimadzu RF 20A, Japan) after derivatization with o-phthaldialdehyde (OPA). For fumonisin derivatization: $100 \mu 1$ of derivatization solution was added to $100 \mu 1$ of sample. The contents were mixed and allowed to react for $2 \mathrm{~min}$ prior to injection. The derivatization solution was prepared by mixing $120 \mathrm{mg}$ of OPA (Sigma-Aldrich, France; P0657), $3 \mathrm{ml}$ of $100 \%$ methanol, $15 \mathrm{ml}$ of $0.1 \mathrm{M}$ Borate buffer $\mathrm{pH} 10$ and $179 \mu \mathrm{l}$ of 1-thioglycerol (SigmaAldrich, France; M2172), and left overnight in the dark at room temperature prior to use. The operating conditions were as follows: injection volume of $100 \mu 1$ of each sample after fumonisin derivatization; C18 reverse-phase column, Uptisphere type, ODB, $5 \mu \mathrm{m}$ particle size, $250 \times 4.6 \mathrm{~mm}$, with identical pre-column, thermostatically controlled at $35^{\circ} \mathrm{C}$; 
isocratic flow rate of $1 \mathrm{~mL} / \mathrm{min}$; mobile phase A was acetonitrile-glacial acetic acid (99:1; $\mathrm{v} / \mathrm{v})$ and mobile phase B was ultrapure water-glacial acetic acid $(99: 1 ; \mathrm{v} / \mathrm{v})$, with gradient conditions: mobile phase A: 41\% (0-9 mins), 61\% (9-16 mins), 100\% (16-20 mins), 41\% (2025 mins); fluorescence detection for fumonisins was set at $335 \mathrm{~nm}$ excitation and $440 \mathrm{~nm}$ emission (Ware et al., 2017). The retention times were 11 min for FB1 and 15 min for FB2. The fumonisin contents were calculated from calibration curves established for FB1 and FB2with standard solutions (TSL-204 and TSL-205 respectively, Biopharm Rhône Ltd, Glasgow, UK). If the measured fumonisin content in a sample was higher than the highest calibration point, the sample was diluted in $0.1 \mathrm{M}$ Borate buffer $(\mathrm{pH} 10)$ and analysed again by HPLC. The percentage of bound fumonisin (FB1 or FB2) by the different LAB strains was calculated using the following equation:

Bound fumonisin (FB1 or FB2) $(\%)=100 \times(1-$ Peak area of fumonisin in the supernatant $)$

Peak area of fumonisin in positive control

The HPLC method was validated by measuring the linearity, recovery, matrix effect, limit of detection (LOD) and limit of quantification (LOQ), as well as the intraday (repeatability) and interday (reproducibility) precisions for each fumonisin (FB1 and FB2).The linearity was evaluated for FB1 and FB2 using the calibration curve of each standard (TSL-204 for FB1 and TSL-205 for FB2) at six concentration levels, ranging from 5 to $500 \mathrm{ng} / \mathrm{ml}$ for each fumonisin. The recovery was calculated by comparison of the response obtained for each fumonisin with the HPLC method and the theoretical fumonisin level in the positive control at the different tested $\mathrm{pH}(2,4,5$ and 6$)$. The intraday and interday precisions were determined by calculating the relative standard deviation $\left(\mathrm{RSD}_{\mathrm{r}}\right.$ for repeatability and $\mathrm{RSD}_{\mathrm{R}}$ for reproducibility) obtained from results generated from the analysis of positive controls at the different tested $\mathrm{pH}$ ( 6 determinations in the same day for repeatability; 2 determinations on 5 consecutive days for the reproducibility). The LOD and LOQ were determined from a signal to noise ratio of 3 and 10 respectively.

\section{Statistical analysis}

All experiments were performed in duplicate and results analysed using a two-way analysis of variance (ANOVA) to determine whether the tested parameters $(\mathrm{pH}$, incubation temperature, storage time and LAB strain) affected the binding interaction and stability between the LAB strains and fumonisins (B1 and B2). A t-test was performed to examine significant differences 
between $\mathrm{pH}$, incubation temperatures $\left(30^{\circ} \mathrm{C}\right.$ and $\left.37^{\circ} \mathrm{C}\right)$, storage time, LAB strains and fumonisins (B1 and B2). Where significant differences were found on the ANOVA test, the Tukey's Honest Significance Difference (HSD) Test based on the studentized range distribution was used to determine for which $\mathrm{LAB}$ strains tested parameters there were significant differences.

\section{Results}

\section{Validation of the HPLC method for FB1 and FB2 analysis}

The performance parameters of the method are given in Table 1. For both fumonisins, the linearity was good ( $\mathrm{R}^{2}$ of 0.9970 for FB1and 0.9976 for FB2) in the range of concentrations comprised between 5 and $500 \mathrm{ng} / \mathrm{ml}$. The LOD and LOQ were $0.3 \mathrm{ng} / \mathrm{ml}$ and $1 \mathrm{ng} / \mathrm{ml}$, respectively, for both FB1 and FB2. The recoveries calculated from results obtained from the analysis of positive controls prepared in $\mathrm{CPB}$ at different $\mathrm{pH}(2,4,5,6)$ were higher for FB1 (75-117\%) than for FB2 (63-71\%) and, for both toxins, within the range (60-120\%) recommended by European Commission (EC) Regulation No 401/2006. The repeatability and reproducibility of the method were satisfactory at all tested $\mathrm{pH}$ with $\mathrm{RSD}_{\mathrm{r}}$ and $\mathrm{RSD}_{\mathrm{R}}$ being lower than the recommended values by EC Regulation No 401/2006 (30 and 60\% respectively).

Table 1: Performance parameters of the HPLC method for fumonisin analysis

\begin{tabular}{|c|c|c|c|c|c|c|}
\hline & Linearity $\mathrm{R}^{2}$ & Recovery $\%$ & LOD ng/ml & LOQ ng/ml & RSD $_{\mathrm{r}} \%$ & $\mathrm{RSD}_{\mathrm{R}} \%$ \\
\hline FB1 & 0.9970 & $75-117^{*}$ & 0.3 & 1 & $3-9 *$ & $9-29^{*}$ \\
\hline FB2 & 0.9976 & $63-71^{*}$ & 0.3 & 1 & $2-4 *$ & $6-32^{*}$ \\
\hline
\end{tabular}

LOD: Limit of detection

LOQ: Limit of quantification

$\mathrm{RSD}_{\mathrm{r}}$ : Relative standard deviation calculated from results generated under repeatability conditions $\mathrm{RSD}_{\mathrm{R}}$ : Relative standard deviation calculated from results generated under reproducibility conditions

* Range of values obtained at the different tested $\mathrm{pH}(2,4,5,6)$

\section{Effect of $\mathrm{pH}$ and temperature on $\mathrm{LAB}$ - fumonisin(B1 and B2) complex}

Baseline quantification of the binding ratio completed at $30^{\circ} \mathrm{C}$ with $\mathrm{pH} 4$, was indicative of fumonisin (B1 and B2) binding occurring for all 4 LAB strains. The ANOVA carried out on the 48 binding ratio values recorded for FB1 and FB2 indicated that LAB strain, $\mathrm{pH}$ and temperature had significant effects on the percentage of bound FB1 and FB2 (Figure 1a and b). Analysis of the quantification of binding ratio in conditions simulating ogi fermentation parameters $\left(30^{\circ} \mathrm{C}\right.$ with $\mathrm{pH}$ decreasing from 6 to 4$)$ showed that for both $\mathrm{FB} 1$ and FB2, the 

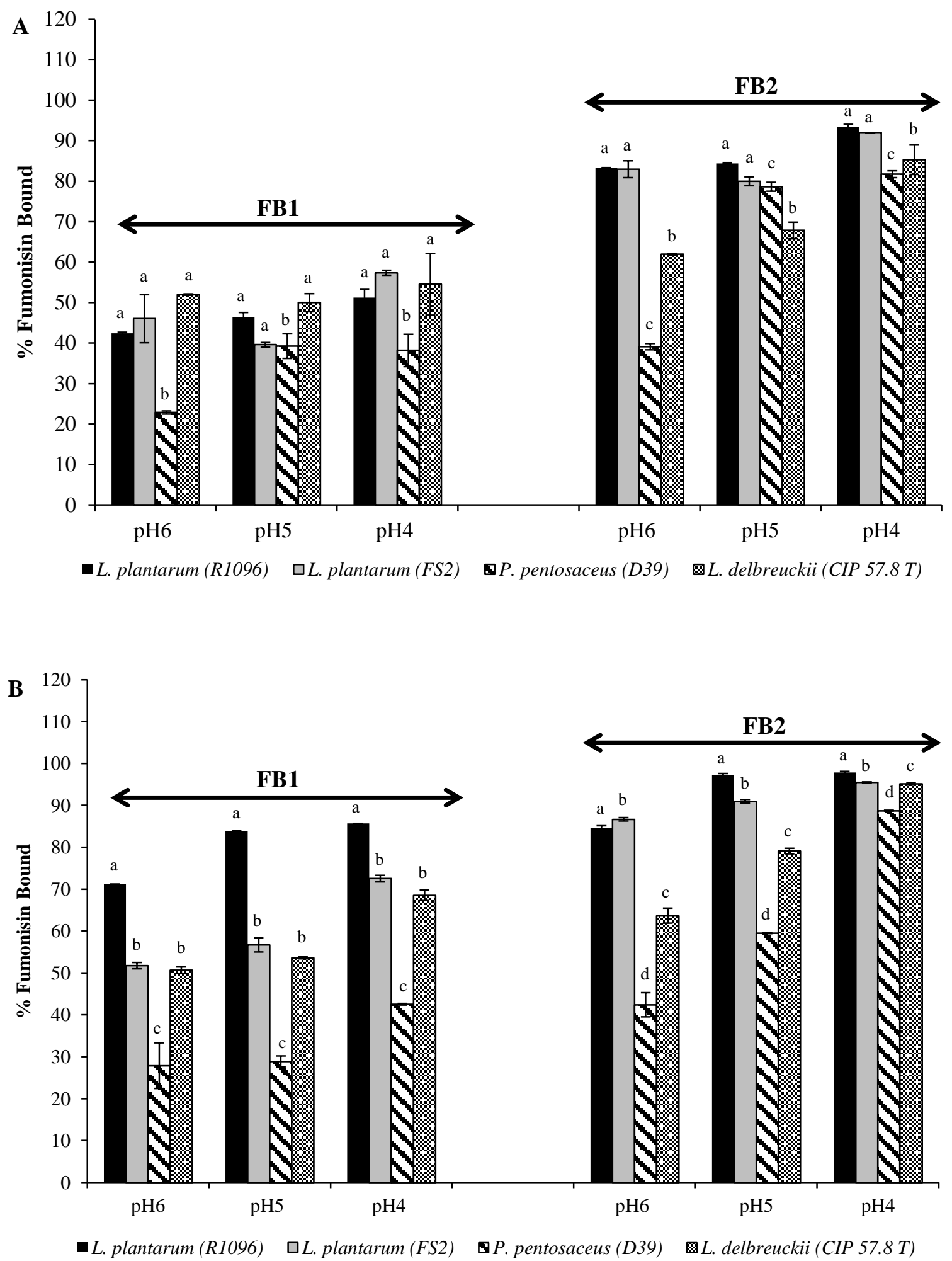

Figure 1: Effect of $\mathrm{pH}$ and temperature on the percentage of fumonisins (B1 and B2) bound by LAB strains: A) at $\left.30^{\circ} \mathrm{C}, \mathrm{B}\right)$ at $37^{\circ} \mathrm{C}$. For each group of bars, the letters indicate the results of the Tukey HSD test on the strains. Strains found to be not different at $95 \%$ significance level are labelled with the same letter 
binding occurred at pH6 (start of fermentation) and the percentage of bound fumonisins increased as $\mathrm{pH}$ decreased to 5 and 4 (end of fermentation) (Figure 1a) (pH significant for FB1 and FB2 with all p-values $<0.0001$ ). The same pattern was observed at $37^{\circ} \mathrm{C}$ (Figure $1 \mathrm{~b}$ ), but the percentage of bound $\mathrm{FB} 1$ and $\mathrm{FB} 2$ was higher at $37^{\circ} \mathrm{C}$ than at $30^{\circ} \mathrm{C}$ (p-value $<0.0001$ for FB1 and p-value< 0.0001 for FB2). Therefore, all 4 LAB strains were able to bind both fumonisins under $\mathrm{pH}$ and temperature conditions tested with strain significant for both FB1 and FB2 (all p-values < 0.0001), but with binding efficiency higher for FB2 (p-value < $0.0001)$.

The Tukey's HSD test indicated significant differences among the 4 LAB strains and the $\mathrm{pH}$ levels, depending on the type of fumonisin (B1 or B2) and the incubation temperature. At $30^{\circ} \mathrm{C}$, the percentage of bound FB1 by $P$. pentosaceus (D39) was significantly lower (23\% at pH 6 and 38\% at pH 4) than by Lactobacillus species: L. plantarum(R1096) (42\% at pH6 and $51 \%$ at $\mathrm{pH} 4$ ), L. plantarum (FS2) (46\% at $\mathrm{pH} 6$ and 57\% at $\mathrm{pH} 4$ ) and L. delbrueckii (CIP $57.8 \mathrm{~T})(52 \%$ at $\mathrm{pH} 6$ and $55 \%$ at $\mathrm{pH} 4)$. At $37^{\circ} \mathrm{C}$, the percentage of bound $\mathrm{FB} 1$ by $P$. pentosaceus (D39) was the lowest (23\% at pH 6 and $43 \%$ at $\mathrm{pH} 4)$, L. delbrueckii(CIP $57.8 \mathrm{~T}$ ) (51\% at pH 6 and $69 \%$ at $\mathrm{pH} 4$ ) and L. plantarum (FS2) (52\% at pH 6 and $73 \%$ at $\mathrm{pH} 4$ ) were similar and L. plantarum (R1096) was the highest ( $71 \%$ at $\mathrm{pH} 6$ and $86 \%$ at $\mathrm{pH} 4$ ). At $30^{\circ} \mathrm{C}$, the percentage of bound FB2 by L. plantarum (FS2) (83\% at $\mathrm{pH} 6$ and 92\% at $\mathrm{pH} 4$ ) was similar to L. plantarum(R1096) (83\% at $\mathrm{pH} 6$ and $93 \%$ at $\mathrm{pH} 4)$, but higher than $L$. delbrueckii (CIP $57.8 \mathrm{~T})(62 \%$ at pH6 and $85 \%$ at pH 4) and P. pentosaceus (D39) (39\% at pH 6 and $82 \%$ at $\mathrm{pH} 4$ ). At $37^{\circ} \mathrm{C}$, the percentage of bound FB2 by P. pentosaceus (D39) (42\% at $\mathrm{pH} 6$ and $89 \%$ at $\mathrm{pH} 4$ ) was also the lowest, then L. delbrueckii (CIP $57.8 \mathrm{~T}$ ) (64\% at pH6 and $95 \%$ at $\mathrm{pH} 4$ ), then L. plantarum (FS2) (87\% at $\mathrm{pH} 6$ and $95 \%$ at $\mathrm{pH} 4$ ), and $L$. plantarum(R1096) (85\% at pH6 and $98 \%$ at $\mathrm{pH} 4$ ) highest.

Figure 2 compares the percentage of fumonisins (B1 and B2) bound by the 4 LAB strains under baseline parameters $\left(\mathrm{pH} 4,30^{\circ} \mathrm{C}\right.$ at the end of ogi fermentation) against lower $\mathrm{pH}$ of 2 and incubation temperature of $37^{\circ} \mathrm{Cfound}$ during human gastric digestion.For all $4 \mathrm{LAB}$ strains and both $\mathrm{FB} 1$ and $\mathrm{FB} 2$, the binding ratio was higher at $\mathrm{pH} 2,37^{\circ} \mathrm{C}$ than at $\mathrm{pH} 4,30^{\circ} \mathrm{C}$ (all p-values <.0001), ranging from $38-57 \%$ to $80-98 \%$ for FB1 and from 82-93\% to $97-100$ $\%$ for $\mathrm{FB} 2$ at $\mathrm{pH} 4,30^{\circ} \mathrm{C}$ and $\mathrm{pH} 2,37^{\circ} \mathrm{C}$, respectively. The percentage of bound $\mathrm{FB} 1$ by $L$. plantarum (R1096) was the highest at $46 \%$, followed by P. pentosaceus (D39) at $42 \%$ with $L$. plantarum (FS2) and L. delbrueckii (CIP $57.8 \mathrm{~T}$ ), similar, at 28\%. The percentage of bound 
FB2 by P. pentosaceus (D39) was the highest at 17\%, followed by L. delbrueckii (CIP 57.8 T) at $14 \%$, L. plantarum (FS2) at 7\% and L. plantarum (R1096) at 5\%. However, amongst the 4 LAB strains, the ANOVA indicated significant differences for FB1 (p-value $=0.0438$ ), but not for FB2 (p-value $=0.1126$ ). Tukey's HSD test applied to the strains for FB1 indicated that $P$. pentosaceus (D39) was significantly lower (38\% at $\mathrm{pH} 4$ and $80 \%$ at $\mathrm{pH} 2)$ than the other three strains L. plantarum (FS2) (57\% at pH 4 and 86\% at pH 2),L. plantarum (R1096) (51\% at $\mathrm{pH} 4$ and $97 \%$ at $\mathrm{pH}$ 2) and L. delbrueckii(CIP $57.8 \mathrm{~T})(54 \%$ at $\mathrm{pH} 4$ and $82 \%$ at $\mathrm{pH} 2$ ). These results indicate not only the stability of the LAB-fumonisin (B1 and B2) complex under lower $\mathrm{pH}$ and incubation temperature of $37^{\circ} \mathrm{C}$, but also an increase in the amount of fumonisins bound by all 4 LAB strains under such conditions, particularly for FB1.

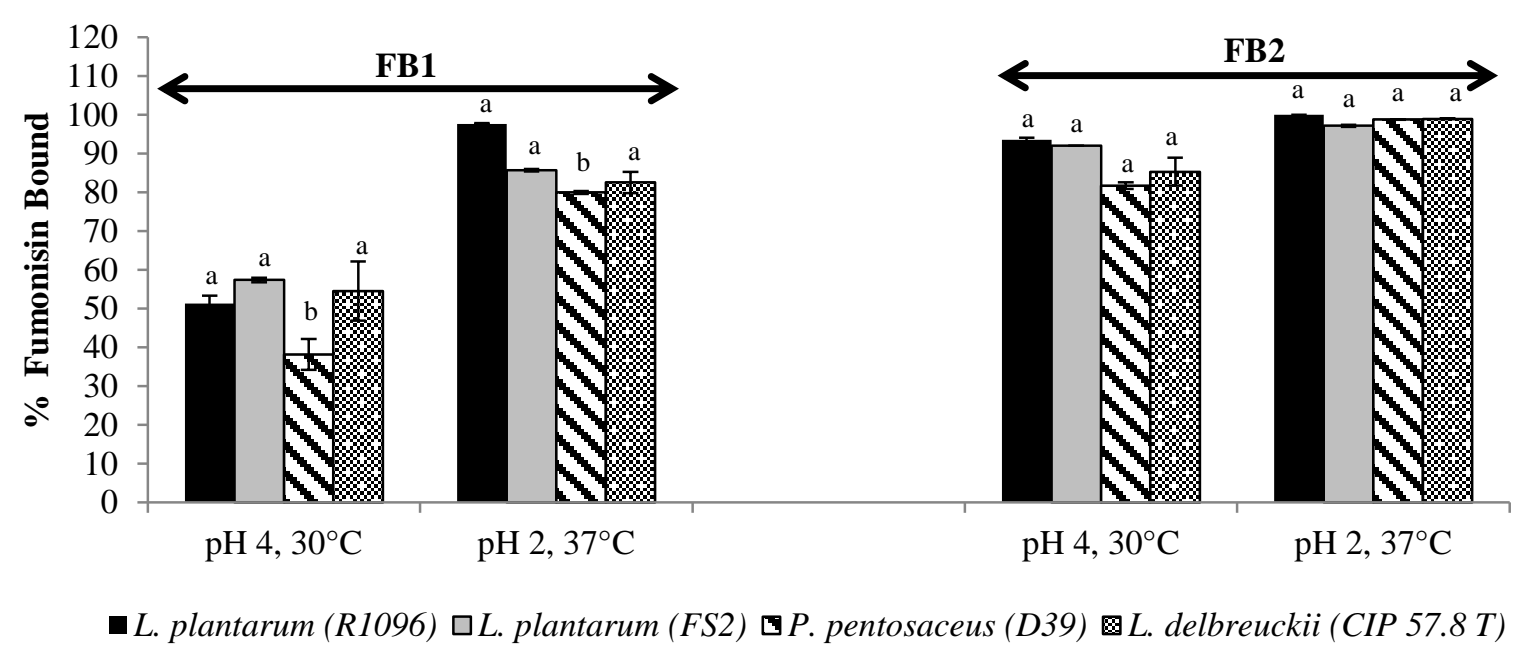

Figure 2: Effect of lower $\mathrm{pH}(2)$ and incubation temperature of $37^{\circ} \mathrm{C}$ in vitro on the stability of $\mathrm{LAB}$ fumonisin (B1 and B2) complex by comparison of the binding ratio under baseline parameters $\left(\mathrm{pH} 4,30^{\circ} \mathrm{C}\right.$ at the end of ogi fermentation). For each group of bars, the letters indicate the results of the Tukey HSD test on the strains.

\section{Effect of simulated ogi storage conditions in vitro on binding stability}

The stability of the LAB-fumonisin (B1 and B2) complex was evaluated during simulated storage conditions $\left(6\right.$ days at $\left.30^{\circ} \mathrm{C}\right)$ of fermented ogi $(\mathrm{pH} 4)$, against baseline parameters $(\mathrm{pH}$ $4,30^{\circ} \mathrm{C}$ at the end of ogi fermentation)(Figure 3). The ANOVA indicated significant differences for both FB1 and FB2 amongst storage times (p-values < 0.0001) and among the 4 LAB strains ( $\mathrm{p}$-value $=0.0005$ for FB1; $\mathrm{p}$-value $<0.0001$ for FB2). The percentage of FB1 and FB2 bound decreased after 6 days of storage for all LAB strains, except for L. plantarum (R1096) for which it increased (from $51 \%$ to $88 \%$ for FB1 and from $93 \%$ to $100 \%$ for 
FB2). The highest decrease in percentage bound for FB1 was L. delbrueckii (CIP 57.8 T) at $29 \%$, followed by P. pentosaceus (D39) at $19 \%$ and L. plantarum (FS2) at $8 \%$ whereas the highest decrease in percentage bound for FB2 was P. pentosaceus (D39) at 67\%, followed by L. plantarum (FS2) at $21 \%$ and L. delbrueckii(CIP $57.8 \mathrm{~T}$ ) at $6 \%$.

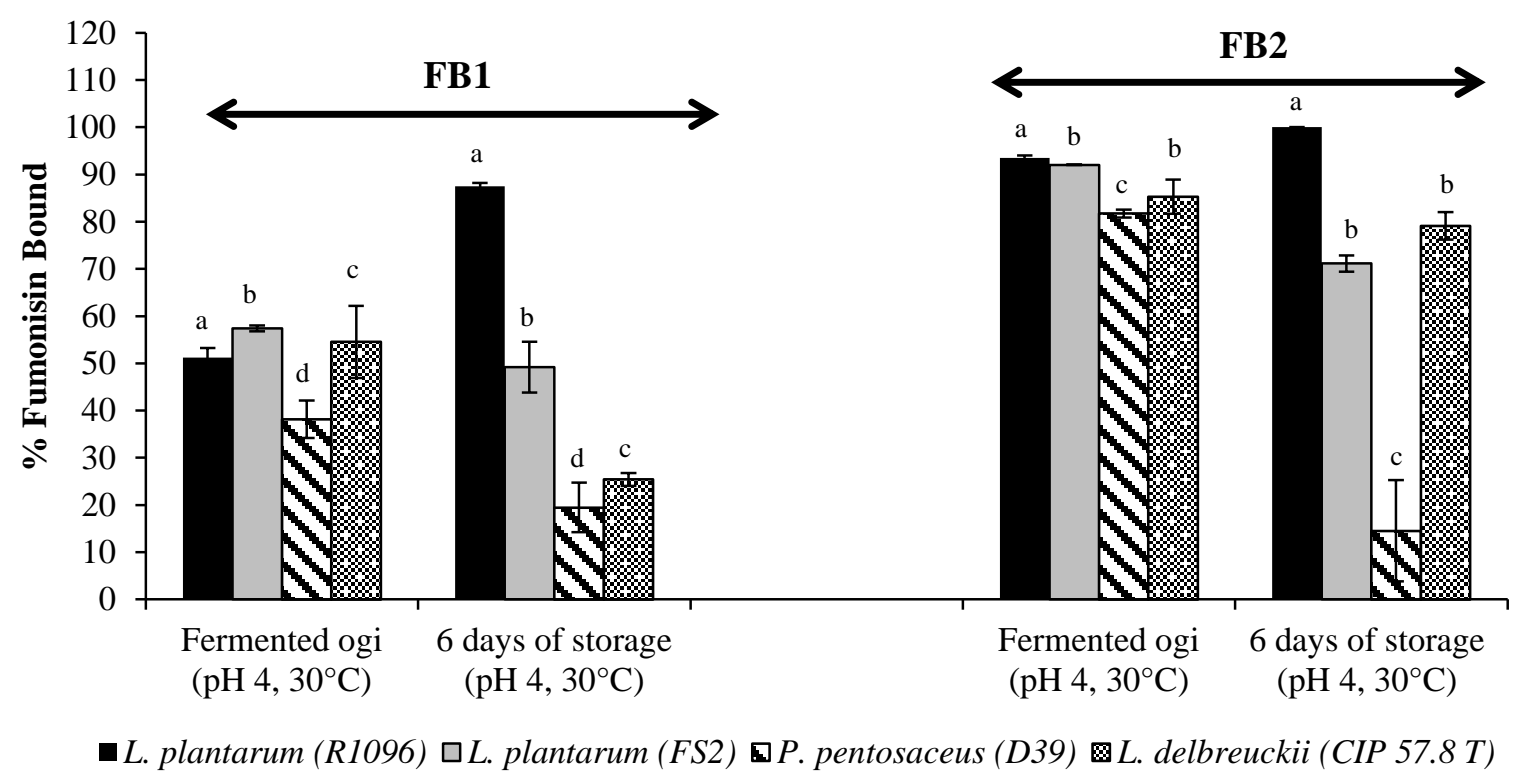

Figure 3: Effect of simulated storage conditions $\left(6\right.$ days at $\left.30^{\circ} \mathrm{C}\right)$ of fermented ogi $(\mathrm{pH} 4)$ in vitro on the stability of LAB - fumonisin (B1 and B2) complex. For each group of bars, the letters indicate the results of the Tukey HSD test on the strains.

\section{Discussion}

The HPLC method used for the analysis of FB1 and FB2 was validated. Successful binding of FB1 and FB2 was observed for all LAB strains tested, with FB2 bound more than FB1. This study also showed that binding of fumonisins increased with a decrease in $\mathrm{pH}$ from 6 to 4 (observed during ogi fermentation process) and from 4 to 2 (acidic $\mathrm{pH}$ in the stomach), and an increase in temperature (from $30^{\circ} \mathrm{C}$ to $37^{\circ} \mathrm{C}$ ). However, as storage time increased (up to 6 days at $\mathrm{pH} 4,30^{\circ} \mathrm{C}$ simulating ogi storage conditions), binding stability decreased for $L$. plantarum (FS2), P. pentosaceus (D39) and L. delbrueckii (CIP $57.8 \mathrm{~T}$ ) and increased for $L$. plantarum(R1096).This work revealed that efficiency in binding FB1 and FB2 varied between strains with Lactobacillus species (L. plantarum and L. delbrueckii) being the most efficient and Pediococcus pentosaceus the less efficient. 
Various authors have reported the binding affinity of LAB strains for mycotoxins (Ahlberg et al., 2015; Dalié et al., 2010) such as aflatoxin B1 (AFB1) (El-Nezami et al.,1998), zearalenone (ZEN) and $\alpha$-zearalenol (El-Nezami et al., 2002), deoxynivalenol, nivalenol, ZEN, FB1 and FB2 (Niderkorn et al., 2006a), AFB1 and patulin (Topcu et al., 2010), and FB1 and FB2 (Zhao et al., 2016) with an effect of bacterial concentration, pH, temperature and incubation time on such binding ability. Niderkorn et al. (2006a) who were the first to evaluate in vitro the binding ability of various LAB strains for FB1 and FB2, obtained 74\% and $97 \%$ binding of FB1 and FB2, respectively, with $10^{10} \mathrm{cfu} / \mathrm{ml}$ of $L$. plantarum (R1096). Niderkorn's protocols with few modifications used in the present study resulted in the achievement of $51 \%$ binding of FB1 and $94 \%$ binding of FB2 for the same LAB strain with bacterial concentration of $10^{13} \mathrm{cfu} / \mathrm{ml}$. Zhao et al. (2016) obtained 53\% binding of FB1 and $85 \%$ binding of FB2 with $10^{9} \mathrm{cfu} / \mathrm{ml}$ of $L$. plantarum B7. Thus these previous investigations, as in the present work, showed a higher binding for FB2 than FB1, but also an increase in fumonisin binding as $\mathrm{pH}$ decreases and temperature increases, and differences in binding efficiency among LAB strains.

Studies have also been conducted to elucidate the mechanism of mycotoxin removal by LAB (Dalié et al., 2010). It was demonstrated that binding is the main mechanism involved in fumonisin removal, with adhesion to LAB cell wall components occurring rather than covalent binding or metabolism (Dalié et al., 2010; Niderkorn et al., 2009; Zhao et al., 2016). Our preliminary results were in agreement with binding mechanism since fumonisin removal was observed in presence of both live and dead LAB (unpublished data). LAB strains are Gram positive and so their cell wall mainly consists of peptidoglycans, teichoic acids, proteins and polysaccharides (Chapot-Chartier and Kulakauskas, 2014; Delcour et al., 1999).It was reported that peptidoglycans of LAB cell wall are the main binding sites for fumonisins, their structural integrity is essential and their amino acid sequence plays an important role in the efficiency of the binding mechanism. TCA chains in fumonisins also are important components in the binding process (Dalié et al., 2010; Niderkorn et al., 2009; Zhao et al., 2016).

Various factors can contribute to and explain the differences observed in the percentage of FB1 and FB2 bound by the four LAB strains used in this study under the parameters tested ( $\mathrm{pH}$, temperature, incubation time): the shape, size and surface area of LAB cells, the 
composition, structure and surface charge of LAB cell walls, and the conformation and electrostatic potential of each fumonisin molecule.

As can be seen from the results, theory vs practical quantification indicates a different hypothesis as to the binding reaction in that theoretically, it was expected that the binding of FB1 and FB2 would be the same due to their similarity in chemical structure as previously reported for zearalenone and $\alpha$-zearalenol by El-Nezami et al. (2002), where both toxins competed for the same binding site. Practical results obtained in the present study and other studies (Niderkorn et al., 2006a, b; Zhao et al., 2016) have indicated otherwise, i.e. higher binding for FB2 than FB1. The only structural variation between FB1 and FB2 consists in an additional hydroxyl group in $\mathrm{C}_{10}$ for FB1. Niderkorn et al. (2006a and 2009) suggested that the spatial conformation resulting from hydrogen bond between this extra hydroxyl group and a carboxyl group may limit the accessibility of FB1 to the binding sites of LAB cell walls.

Statistical analyses have indicated that binding affinity of LAB strains for FB1 and FB2 is significantly affected by temperature ( $\mathrm{p}$-value $<0.001$ ) and $\mathrm{pH}$ (p-value $<0.0001)$. The combination of higher incubation temperature $\left(37^{\circ} \mathrm{C}\right)$ and low $\mathrm{pH}$ (4) produced the highest binding of FB1 and FB2 by all the LAB strains tested (p-value $<0.0001$ ). The increase in incubation temperature from $30^{\circ} \mathrm{C}$ to $37^{\circ} \mathrm{C}$ is the factor that illustrated a direct relationship to the increase in fumonisin binding. LAB grows optimally at $37^{\circ} \mathrm{C}$ where the cells prepare for growth either by "make before break" or "inside to outside" principle as explained by Delcour et al. (1999). In both principles, more peptidoglycans are added to the cell wall (Delcour et al., 1999) providing more favourable binding sites for FB1 and FB2 (Delcour et al., 1999; Niderkorn et al., 2009; Zhao et al., 2016), hence enhanced binding.

The increase in fumonisin binding rate as the $\mathrm{pH}$ decreases from 6 to 2 could be attributed to the change in $\mathrm{pH}$ affecting the surface charge in the constituents of the LAB cell wall providing favourable binding sites for each of the fumonisins (Luxbacher, 2014; ScharZammaretti and Ubbink, 2003).Zhao et al. (2016) gave two explanations for this result. The first one is that acidic $\mathrm{pH}$ would broke bonds among certain constituentsof the LAB cell wall altering its original structure in a way that would provide more favourable binding sites for FB1 and FB2. The second one is that under acidic conditions hydrolysis of TCA structure in fumonisins may be inhibited permitting increased binding with LAB cell wall as TCA structure plays an important role in the binding process. 
The variation in fumonisin binding efficiency observed among the four LAB strains could be explained by thedifference in shape, size and surface area of LAB cells i.e. bacilli rods vs cocci. It is well known that bacilli rods tend to occur singularly with a cell size of 0.19 $1.2 \mu \mathrm{m} \times 3-8 \mu \mathrm{m}$ (Pederson, 1935) whereas cocci tend to occur in tetrads with a single cocci cell size of 0.5 - $1 \mu \mathrm{m}$ (Semjonovs, 2010). Due to the cocci preference of occurring in tetrads, this arrangement drastically reduces the surface area of binding sites for FB1 and FB2. $P$. pentosaceus (D39) had the lowest binding affinity for FB1 and FB2, whereas the Lactobacillus species showed the most binding affinity.Over time the tetrads auto-aggregate as per their natural preference (Holzapfel et al., 2006) and this characteristic, further drastically reduces the binding. Jankovic et al. (2012) also demonstrated that Lactobacillus strains possess the ability to auto-aggregate with after $24 \mathrm{~h}$ at least $80 \%$ of Lactobacillus aggregated. The decrease of binding ratio over time (i.e. under simulated ogi storage conditions) for the three LAB strains, P. pentosaceus (D39), L. plantarum (FS2) and $L$. delbrueckii (CIP 57.8 T), could also be an indication that during storage these strains have a tendency to auto-aggregate, which is one of the desirable attributes of a probiotic (Jankovic et al., 2012).

Differences in binding efficiency among LAB strains could also be explained by the fact that the genetic differences between each strain would produce different components in the cell wall (i.e. peptidoglycans, teichoic acids, polysaccharides and proteins) that could or could not enhance binding affinity for FB1 and FB2 (Schar-Zammaretti and Ubbink, 2003). In particular, the molecular structure of peptidoglycans which are the main binding sites for FB1 and FB2, varies with bacterial species (Niderkorn et al., 2009; Zhao et al., 2016).

\section{Conclusion}

LAB species (L. plantarum, L. delbrueckii ssp. delbrueckii and Pediococcus pentosaceus) that are predominant in African traditional fermented maize based foods (ogi and mahewu) have been successfully evaluated in binding FB1 and FB2. Assessment of the binding ratio and complex stability under varying parameters of $\mathrm{pH}$, temperature and incubation time indicated that the four LAB strains used in this study have the ability to bind FB1 and FB2, with all the strains exhibiting higher binding for FB2 than FB1.Binding ratio increased with a decline in $\mathrm{pH}$ from 6 to 2 and an increase in incubation temperature from $30^{\circ} \mathrm{C}$ to $37^{\circ} \mathrm{C}$. Nevertheless, the percentage of $\mathrm{FB} 1$ and $\mathrm{FB} 2$ bound to $\mathrm{LAB}$ at $\mathrm{pH} 4,30^{\circ} \mathrm{C}$ decreased after 6 
days of storage at $30^{\circ} \mathrm{C}$ for all tested LAB strains, except for the positive control strain, $L$. plantarum (R1096), for which it increased.These results indicate the stability of the LABfumonisin (B1 and B2) complex under conditions of $\mathrm{pH}$ and temperature observed during ogi fermentation and in the stomach(and even an increase in the fumonisins bound by the LAB strains under such conditions) but not after 6 days under ogi post fermentation storage conditions. In addition, FB1 and FB2 binding efficiency varied between LAB strains, with Lactobacillus species being the most efficient in binding fumonisins whereas Pediococcus $s p$. the less efficient. This therefore suggests the potential for these Lactobacillus species to be used as main starter culture in African traditional fermented maize based foods specifically, ogi and mahewu, with a twofold advantage of being a probiotic coupled with ability to reduce the toxicity of fumonisins. However, this requires that the efficiency of $L$. plantarum and $L$. delbrueckii strains in binding fumonisins will be evaluated in the full matrix, i.e. during ogi and mahewu fermentation, with the analysis of both hidden and bound fumonisins, as well as the effect of these strains on the physicochemical and sensory properties of the final fermented maize products to establish consumer acceptability. In addition, the binding ratio and complex stability under proper simulated human gastric digestion and the toxicity of the complex LAB-fumonisin (B1 and B2) should be tested.

\section{Acknowledgements}

This publication is resulting from a research project funded by the European Union (FP7 245025) called African Food Revisited by Research (AFTER - http://www.afterfp7.eu/) and from a French-South African PHC Protea project (Project N²9769VL). The views expressed are not necessarily those of the European Union.

\section{References}

Abrunhosa, L., Morales, H., Soares, C., Calado, T., Vila-Chã, A.S., Pereira, M. and Venâncio, A. 2016. A Review of Mycotoxins in Food and Feed Products in Portugal and Estimation of Probable Daily Intakes. Critical Reviews in Food Science and Nutrition. 56(2): 249-265.

Adebayo-tayo, B.C. and Onilude, A.A. 2008. Screening of Lactic Acid Bacteria Strains Isolated from Some Nigerian Fermented Foods for EPS Production. World Applied Sciences Journal. 4 (5): 741-747. 
Afolabi, O.R. and Akintokun, A.K. 2008. Inhibition of some intestinal pathogens by Lactobacillus species isolated from ogi. Asset Series B. 7(1): 10-16.

Agati, V., Guyot, J.P., Morton-Guyot, J., Talamond, P. and Hounhouigan, D.J. 1998. Isolation and characterization of new amylolytic strains of Lactobacillus fermentum from fermented maize doughs (mawe and ogi) from Benin. Journal of Applied Microbiology.85:512-520

Agence Française de Sécurité Sanitaire des Aliments (AFSSA). French Food Safety Agency. 2006. Risk assessment for mycotoxins in human and animal food chains. 76pp.

Ahlberg, S.H., Joutsjoki, V. and Korhonen, H.J. 2015. Potential of lactic acid bacteria in aflatoxin risk mitigation. International Journal of Food Microbiology 207. 87-102

Beier, R. C., Elissalde, M. H. and Stanker L.H. 1995. Calculated three dimensional structures of the fumonisin B1-4 mycotoxins. Bulletin of Environmental Contamination and Toxicology. 54: 479-487.

Beier, R.C. and Stanker, L. H. 1997. Molecular models for the stereochemical structures of FB1 and FB2. Archives of Environmental Contamination and Toxicology. 33: 1-8.

Chapot-Chartier, M.P. and Kulakauskas, S. 2014. Cell wall structure and function in lactic acidbacteria. Microbial Cell Factories. 13(1):S9.

Chilaka, C.A., De Boevre, M., Atanda, O.O. and De Saeger, S. 2016. Occurrence of Fusarium mycotoxins in cereal crops and processed products (Ogi) from Nigeria. Toxins. 8: 342-360.

Dalié, D.K.D., Deschamps, A.M. and Richard-Forget, F. 2010. Lactic acid bacteria Potential for control of mould growth and mycotoxins: A review. Food Control. 21: 370-380.

Dawlal, P., Barros, E. and Marais, G.J. 2010. Resistance of maize cultivars against the infestation of mycotoxigenic fungi. Master's thesis. University of Pretoria. 203 pp.

Delcour, J., Ferrain, T., Deghorain, M., Palumbo, E. and Hob, P. 1999. The biosynthesis and functionality of the cell wall of lactic acid bacteria. Antonie van Leeuwenhoek. 76: 159-184. 
De Man, J. C., Rogosa, M. and Sharpe, M. E. 1960.A medium for the cultivation of Lactobacilli. Journal of Applied Bacteriology. 23: 130-135.

El-Nezami, H., Kankaanpaa, P., Salminen, S. and Ahokas, J. 1998. Ability of dairy strains of Lactic acid bacteria to bind a common food carcinogen, Aflatoxin B1. Food and Chemical Toxicology. 36:321-326.

El-Nezami, H., Polychronaki, N., Salminen, S. and Mykkänen, H. 2002. Binding rather than metabolism may explain the interaction of two food-grade Lactobacillus strains with zearalenone and its derivative $\alpha$-zearalenol. Applied and Environmental Microbiology. 68(7): 3545-3549.

European Commission (EC). 2006. Commission Regulation No 401/2006 of 23 February 2006 laying down the methods of sampling and analysis for the official control of the levels of mycotoxins in foodstuffs. Official Journal of the European Union. L 70: 12-34.

Fayemi, O. E. 2016. Inhibition of non-0157 Shiga toxin producing Escherichia coli in African fermented foods by probiotic bacteria. Doctoral Thesis. University of Pretoria. 150pp.

Ferrigo, D., Raiola, A. and Causin, R. 2016. Fusarium Toxins in Cereals: Occurrence, Legislation, Factors Promoting the Appearance and Their Management. Molecules. 21: 627.

Food and Agricultural Organisation (FAO). 1999. Fermented cereals. A global perspective. Cereal fermentations in African countries. Chapter 2.Version 138.FAO Agricultural Services Bulletin.

Food and Agricultural Organisation (FAO) Statistical Yearbook. 2014. Asia and the Pacific Food and Agriculture. 177pp. Bangkok. FAO Statistical Services.

Hammes, W.P. and Hertel.C. 2011. Genus I: Lactobacillus Beijerinck 1901. Pg. 490. Family I: Lactobacillae Winslow, Broadhurst, Buchanan, Krumwiede, Rogers and Smith 1917 Familia. Schleifer, K.H. Pg. 466. In Bergey's Manual of Systemic Bacteriology: Volume 3: The Firmicutes. Edited by de Vos, P., Boone, D.R., Garrity, G.M., Castenholz, R.W., Brenner, D.J., Krieg, N.R. and Staley J.T. 2011.Springer. 1476pp 
Holzapfel, W.H., Franz, C.M.A.D., Ludwig, W., Back, W and Dicks, L.M.T. 2006. The Genera: Pediococcus and Tetragenococcus. Chapter: 1.2.8. Pg. 229. In: The Prokaryotes: Vol.4: Bacteria: Firmicutes, Cyanobacteria. Eds. Falkow, S., Rosenberg, E., Schleifer, K.H. and Stackebrandt, E. Springer Science and Business Media.

Holzapfel, W.H. and Taljaard, J.L. 2004. Industrialization of mageu fermentation in South Africa. Page 363. Chapter 7 in Industrialization of Indigenous Fermented Foods. Edited Steinkraus, K.H. CRC Press. 600pp.

Ijabadeniyi, A.O. 2007. Microorganisims associated with ogi traditionally produced from three varieties of maize. Research Journal of Microbiology. 2(3): 247-253.

International Agency for Research on Cancer (IARC). 2015. Mycotoxin control in low- and middle-income countries. Eds. Wild, C.P., Miller, D. and Groopman, J.D. 66pp. IARC Library Cataloguing in Publication Data.

Jacobs, A. 1991. Section IV: Method of freezing lactic acid bacteria. In Biological Control Project: Manual of Methods. 100pp.

Jankovic, T., Frece, J., Abram, M. and Gobin, I. 2012. Aggregation ability of potential probiotic Lactobacillus plantarum strains. International Journal of Sanitary Engineering Research. 6(1): 19-24.

Jard, G., Liboz, T., Mathieu, F., Guyonvarc'h, A. and Lebrihi, A. 2011. Review of mycotoxin reduction in food and feed: from prevention in the field to detoxification by adsorption or transformation. Food Additives and Contaminants: Part A. 1-20.

Kabak, B. 2009. The fate of mycotoxins during thermal food processing. Journal of the Science of Food and Agriculture. 89: 549-554.

Karlovsky, P., Suman, M., Berthiller, F., de Meester, J., Eisenbrand, G., Perrin, I., Oswald, I.P., Speijers, G., Chiodini, A., Recker, T. and Dussort, P. 2016. Impact of food processing and detoxification treatments on mycotoxin contamination. Mycotoxin Research. 32:179-205. 
Katangole, J.N. 2008. The Microbial Succession in Indigenous Fermented Maize Products. Masters thesis. University of Free State. 150pp.

Luxbacher, T. 2014. The zeta guide. Principles of the streaming potential technique. $1^{\text {st }}$ edition. Anton Paar GmbH. 138 pp.

Macauley, H. and Ramadjita, T. R. 2015.Cereal Crops: Rice, Maize, Millet, Sorghum, Wheat. An Action Plan for African Agricultural Transformation. Feeding Africa. United Nations: Economic Commission for Africa. 36pp.

Mngqawa, P., Shephard, G. S., Green, I. R., Ngobeni, S. H., de Rijk, T. C. and Katerere, D. R. 2016. Mycotoxin contamination of home-grown maize in rural northern South Africa (Limpopo and Mpumalanga Provinces).Food Additives and Contaminants: Part B. 9 (1): 3845.

Marasas, W.F.O., Gelderblom, W.C.A., Shephard, G.S. and Vismer, H.F. 2008. Mycotoxins: a global problem. Chapter 4.Pg. 29. In Mycotoxins: detection methods, management, public health and agricultural trade. Eds. Leslie, J.F., Bandyapadhyay, R. and Visconti, A. CAB International.

Mugcoba, T. P. 2001. Fermentation of a finger millet-dairy composite gruel. Doctoral thesis. University of Pretoria. 184pp.

Nago, M.C., Hounhouigan, J.D., Akissoe, N., Zanou, E. and Mestres, C. 1998. Characterization of the Beninese traditional ogi, a fermented maize slurry: physicochemical and microbiological aspects. International Journal of Food Science and Technology. 33: 307315.

Niderkorn, V., Boudra, H., Morgavi, D.P. 2006a. Binding of Fusarium mycotoxins by fermentative bacteria in vitro. Journal of Applied Microbiology. 101: 849-856

Niderkorn, V., Morgavi, D.P., Aboab, B., Lemaire, M. and Boudra, H. 2009. Cell wall component and mycotoxin moieties involved in the binding of fumonisin B1 and B2 by lactic acid bacteria. Journal of Applied Microbiology. 106: 977-985. 
Niderkorn, V., Pujos, E., Tissandier, A. and Boudra, H. 2006b. Screening of fermentative bacteria for their ability to bind and biotransform deoxynivalenol, zearalenone and fumonisins in an in vitro model simulating corn silage. Food Additives and Contaminants. 24 (4): 406-415.

Nwosu, V.C. and Oyeka, C.A. 1998. Microbiological succession occurring during fermentation of ogi-an African breakfast cereal. The Journal of the Elisha Mitchell Scientific Society. 114(4): 190-198.

Okeke, C.A.,Ezekiel, C.N., Nwangburuka, C.C., Sulyok, M., Ezeamagu, C.O., Adeleke, R.A., Dike, S.K. and Krska, R. 2015. Bacterial diversity and mycotoxin reduction during maize fermentation (Steeping) for ogi production. Frontiers in Microbiology. 6: 1402-1414.

Omemu, A.M. 2011. Fermentation dynamics during production of ogi, a Nigerian fermented cereal porridge. Report and Opinion. 3(4): 8-17.

Pederson, C.S. 1935. A study of the species of Lactobacillus plantarum (Orla-Jensen) Bergey et al. Journal of Bacteriology. 31(3):217-224.

Pereira, V.L., Fernandes, J.O. and Cunha, S.C. 2014. Mycotoxins in cereals and related foodstuffs: A review on occurrence and recent methods of analysis. Trends in Food Science and Technology. 36: 96-136.

Reddy, K.R.N., Farhana, N.I., Salleh, B. and Oliveira, C.A.F. 2010. Microbiological control of mycotoxins: Present status and future concerns. Current Research, Technology and Education Topics in Applied Microbiology and Microbial Biotechnology.1078-1086.

Schar-Zammaretti, P. and Ubbink, J. 2003. The cell wall of lactic acid bacteria: surface constituents and macromolecular conformations. Biophysical Journal. 85: 4076-4092.

Semjonovas, P. and Zikmanis, P. 2010. Pediococcus pentosaceus lactose-positive strain and a complex of fructan-containing exopolysaccharides synthesized by the strain. 12pp. 
Topcu, A., Bulat, T., Wishah, R. and Boyaci, I.H. 2010. Detoxification of aflatoxin B1 and patulin by Enterococcus faecium strains. International Journal of Food Microbiology. 139: 202-205.

Udomkun, P., Wiredu, A.N., Nagle, M., Bandyopadhyay, R., Müller, J. and Vanlauwe, B. 2017. Mycotoxins in Sub-Saharan Africa: Present situation, socio-economic impact, awareness, and outlook. Food Control. 72: 110-122.

Valiuškaitè, A., Survilienè, E., Lugauskas, A. and Levinskaitė, L. 2006. Ecological aspects of distribution of potential toxin-producing micromycetes on stored apple fruit. Ekologija. 3: $60-93$.

Vismer, H.F., Shephard, G.S., Rheeder, J.P., van der Westhuizen, L. and Bandyopadhyay, R. 2015. Relative severity of fumonisin contamination of cereal crops in West Africa. Food Additives \& Contaminants: Part A. 1-7.

Ware, L. Y., Durand, N., Nikiema, P.A., Alter, P., Fontana, A., Montet, D., and Barro, N. 2017. Occurrence of mycotoxins in commercial infant formulas locally produced in Ouagadougou (Burkina Faso). Food Control. 73: 518-523.

Zain, M.E. 2011. Impact of mycotoxins on humans and animals. Journal of Saudi Chemical Society. 15: 129-144.

Zhao, H., Wang, X., Zhang, J., Zhang, J. and Zhang, B. 2016. The mechanism of Lactobacillus strains for their ability to remove fumonisins B1 and B2. Food and Chemical Toxicology. 97: 40-46. 